\title{
Application of the Servqual method to analyze the satisfaction level of hotel services and facilities
}

\author{
Nur Ainun ${ }^{1)^{*}}$, Volvo Sihombing ${ }^{2)}$, Masrizal ${ }^{3)}$ \\ 1) 2) 3) Labuhan Batu University, Rantauprapat, Indonesia \\ ${ }^{1)}$ nurainunsaya0105@ gmail.com, ${ }^{2}$ volvolumbantoruan@ @mail.com, ${ }^{3}$ masrizal120405@gmail.com
}

Submitted: Feb 2, 2021 | Received: Mar 23, 2021 | Published: Apr 2, 2021

\begin{abstract}
With so many hotels and other accommodation facilities in the city of Medan. More and more people are coming and staying and using the facilities at each hotel. Whether it's rooms, meeting room facilities, facilities to hold events, and much more are available in every hotel. Every hotel wants to give satisfaction to guests who come to use the hotel facilities and services. Likewise with SwissbeliNN hotels which have a 3 (three) star classification. Therefore, the opinions of guests and complaints given are very useful to improve the quality of hotel services. To find out, we will look at the satisfaction level of each guest. In this case, the writer applies the servqual method to see the level of guest satisfaction that has been obtained. To find out what is still lacking in the services provided. The purpose of this research is to find out the shortcomings of the hotel for the services provided to hotel visitors, as well as to fulfill the complaints of each visitor to the hotel from the results of the research carried out, with the objectives described later to be able to provide solutions to hotel leaders to fulfill the research results. obtained. The research methods carried out include collecting data directly from the hotel related to the problems that arise to be researched, literature studies, analyzing the problems to be studied based on the data collection that has been obtained, designing applications to overcome problems that arise and making it easier to find out the level of satisfaction of visitors. against managed hotels, as well as testing applications that are made to test the level of success obtained from the application being built. Based on the research conducted, the average perceived service quality score was 3.54 . This score is in the somewhat unsatisfactory category when compared with the average score of service quality score which is perceived to be lower than expected. This indicates a gap. The highest average score is given to responsiveness with a value of 3.62 while the lowest score is given to the dimension of empathy with a value of 3.44 .
\end{abstract}

Keywords: Microsoft Access 2007, Satisfaction level analysis, Service, Servqual Method, Visual Basic

\section{INTRODUCTION}

With so many immigrants from outside Sumatra heading to Medan, either to visit for work, or to do some event activities, or just for a vacation. Newcomers will of course visit the hotel either to hold activities or just to stay overnight, depending on the type of activities and funds they have and what facilities they want.

When checking in, problems are often encountered, namely when the check-in process is too long because the hotel seems slow. Room quality is also a problem when guests will stay. The attitude and friendliness of hotel workers is also an assessment for guests. Guests will feel comfortable if there are employees / servants who provide the best service. Can provide satisfaction for guests who stay. Many other things can affect the satisfaction level of guests staying at the hotel. (Susepti et al., 2017)

A very important concern is serving hotel guests, whether staying overnight or just using the hotel facilities for the events they hold. This analysis measures hotel guest satisfaction by calculating the difference in discrepancy between what should be and the reality that is felt (Susilo et al., 2018). Customer satisfaction depends on differences in desires (expectations) (Hutauruk, 2016). Thus hotel guests will feel satisfied if there is 
no difference between what is desired and perceptions, in the statement with the desired minimum limit has been met, it will increase the percentage of hotel service users. (Arianto, 2018)

The many problems that occur when hotel guests use hotel services make each hotel have to continue to develop its quality. Many complained about the dissatisfaction they did not get during their stay. This can be obtained from hotel facilities or services provided by hotel staff.

Finally, researchers collected data and observed various problems with the services provided by hotel staff. That way the hotel can improve the services provided to guests. In this study, it was determined that the most important role was the hotel owner to determine the level of satisfaction experienced by visitors to the managed hotel. To process according to the stages given in the application, it is controlled by the assigned IT, and the report form of the results obtained is submitted to the hotel leader. With the aim of correcting the deficiencies of the service requested based on the results of the tests carried out.

\section{Definition of Satisfaction}

\section{LITERATURE REVIEW}

Satisfaction is a pleasant or unpleasant emotional state in which employees view their work. Job satisfaction reflects a person's feelings about his job. (Kaswan, 2017) Meanwhile (Sabariah, 2015) defines satisfaction as a feeling of pleasure or disappointment that a person experiences after comparing the perceived performance or results of a product with his expectations. (Fakhriani \& Rimiyati, 2016) concludes a simple definition of job satisfaction, namely a person's feelings about his job. This kind of conception views satisfaction as the result of human and environmental interactions. So this kind of determination includes individual differences and work situations.

\section{Servqual Method}

Servqual method is a method used to measure the quality of service from the attributes of each dimension, so that the value of the gap will be obtained, namely the difference between consumer perceptions of the service that has been received and the expectations that will be obtained. received. The measurement of this method is by measuring the service quality attributes of each dimension so that the value gap will be obtained which is the difference between consumer perceptions of the service received and consumer expectations of the service to be received. However, in general there is no uniformity of limitations regarding the concept of service quality (servqual). (Prananda et al., 2019).

The servqual method has two perspectives, namely an internal perspective and an external perspective. External perspective is used to understand what is expected, felt, and customer satisfaction. The measurement uses the servqul method. Dyck et al (1997), servqual is a tool for measuring service quality based on information from service providers. Meanwhile, the internal perspective identifies with zero defects and gets it right the first time, adapting to demand. To measure the internal perspective that is free of errors (zero defect) related to service quality, the six sigma method is used. Six sigma is a set of tools used to identify, analyze, and eliminate sources of variation in processes (Ekasari et al., 2017).

The Servqual scale includes five dimensions of service quality, namely; Tangibles, Reliability, Responsiveness, Assurance, and Empathy. Each dimension has several questions and is answered in the range of values 1 to 7, where the number 1 represents the feeling of strongly disagree and the number 7 represents the feeling of strongly agreeing, for a total of 22 questions. -5 dimensions above, namely:

1. Tangibles (measurable evidence), describes the physical facilities, equipment, and appearance of personnel and the whereabouts of users.

2. Reliability (reliability), refers to the ability to provide the promised service accurately and reliably.

3. Responsiveness (responsiveness) namely the willingness to help customers and pay proper attention.

4. Guarantee (guarantee), are polite and knowledgeable employees who give a sense of confidence and confidence.

5. Empathy (empathy), including individual care and concern for the user.

\section{METHOD}

To solve the problem in this research, it is necessary to take steps to solve the problem with several steps in the research method as follows: 


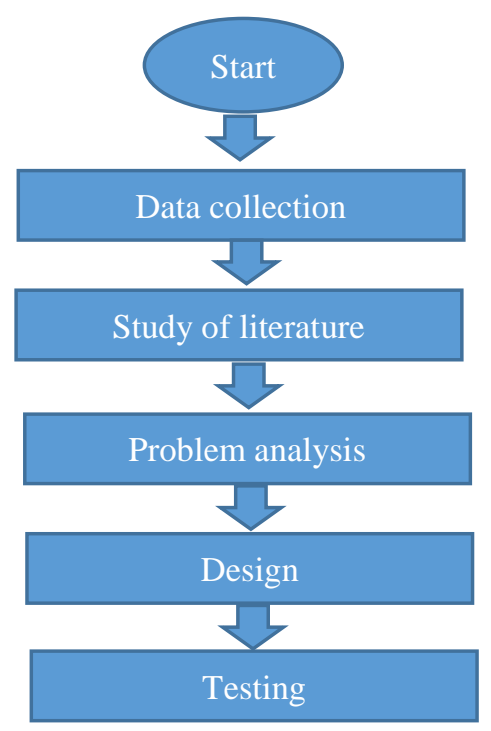

Fig 1. Research Stages

Description of Research Stages:

1. Field Research (data collection)

One of method collection data conducted directly on the object of research to collect the data needed in this study.

a. Interview

Collecting data through direct interviews with hotel service users and managers of the Swiss-BeliNN Medan Hotels in North Sumatra and prospective hotel guests who are currently using lodging services at Swiss-BeliNN Hotel Medan.

b. Observation

the stages of the data collection method by means of observation and learning about the service methods applied to the Swiss-BeliNN Medan Hotel.

2. Study of literature

Researchers conducted a literature study on the application of descriptive methods in analyzing service user satisfaction Hotel Swiss-BeliNN Medan.

3. Problem analysis

Analyze where problems occur in the hotel guest check-in service process.

4. Design

This research was conducted by collecting hotel guest complaint data, the data is in the form of ten questions made by researchers and distributed to consumers then the data is processed using descriptive methods.

5. Test

The system testing stage is the stage for studying and analyzing the problem under study to make problem solving for existing developments.

\section{Questionnaire Results}

\section{RESULTS}

The data from the questionnaire in this study contained 10 questions about service quality. The number of questionnaires distributed to guests at the Swiss-BuyNN hotel service work unit is as follows:

The numbers are being distributed 150 respondents

Who is back

120 respondents

That which is processed

120 questionnaires

The identity of the respondents from the questionnaire results is arranged based on the respondent's answer, age level, gender, and education level of the respondent can be seen in the following table: 
Table 1

Respondent identity based on age level

\begin{tabular}{cccc}
\hline \hline Not. & Respondent Age & Frequency & Percentage (\%) \\
\hline 1. & 20 to 30 years & 65 & 54 \\
2. & 31 to 40 years & 28 & 24 \\
3. & 41 to 50 years & 27 & 22 \\
& total & 120 & 100
\end{tabular}

Based on the information in the table above, it can be concluded that the respondents are between 20 and 50 years old. The data above shows that most of the respondents who participated in this study were between 20-30 years old, that is $(54 \%)$. Viewed from the perspective of consumer behavior, the age of respondents in this group is a critical age in responding or providing quality services.

Table 2

Respondent identity based on gender

\begin{tabular}{cccc}
\hline \hline Not. & Gender & Frequency & Percentage (\%) \\
\hline 1. & Men & 50 & 42 \\
2. & Woman & 70 & 58 \\
& total & 120 & 100
\end{tabular}

Based on the table above, the largest number of respondents were women (58\%) compared to men (42\%).

Table 3.

Respondent identity based on education level

\begin{tabular}{cccc}
\hline \hline Not. & education & Frequency & Percentage (\%) \\
\hline 1. & $\begin{array}{c}\text { Senior High School } \\
\text { equivalent }\end{array}$ & 78 & 65 \\
2. & Bachelor (D-3) & 22 & 18 \\
3. & Bachelor's degree) & 20 & 17 \\
& total & 120 & 100
\end{tabular}

If you look at the data on the distribution of respondents based on education. This study found that $(65 \%)$ of the respondents had a high school education background equivalent to the total selected respondents. After getting the data, the next process is to test the adequacy of the data. This test is carried out to determine whether the amount of data collected is sufficient or not. The minimum sample size calculation required is as follows.

$\mathrm{P}=$ actual proportion $=120 / 125=0.96$

$\mathrm{Q}=$ Wrong proportion $=5 / 125=0.04$

$$
n \geq \frac{\left(Z_{a / 2}\right) \cdot p \cdot q}{e^{2}}
$$

Where:

$\mathrm{n}=$ Number of samples required

$\mathrm{P}=$ opportunity to process the questionnaire

$\mathrm{Q}=$ Opportunity to receive unprocessed questionnaires

$\mathrm{Z}=$ Value from normal distribution

$\mathrm{e}=$ error rate

$\sigma=$ The confidence level used

Based on the normal distribution table with $\sigma=5 \%$ and the confidence level used is $95 \%$, the Ztable value is obtained:

Ztabel $=\mathrm{Z}^{1 / 2}(1-\sigma)$

Ztabel $=1 / 2(1-0.05)$ 
Ztabel $=1.96$

Furthermore, $\mathrm{t}$ count the minimum number of questionnaires needed are:

$$
\begin{aligned}
& P=\frac{120}{125}=0,96 \\
& Q=1-P=0,04 \\
& n \geq \frac{\left(Z_{a / 2}\right) \cdot p \cdot q}{e^{2}}=n \geq \frac{(1,96)^{2} \times 0,96 \times 0,04}{(0,05)^{2}} \\
& n \geq \frac{0,1476}{0,0025}=59
\end{aligned}
$$

Descriptive analysis aims to present a summary of the statistical results of data processing based on the questionnaire filled out by the respondents. The gap between what is expected and what is felt. The results of data processing regarding the quality of service expected by the participants obtained an average value of 4.80 . This value is close to the highest value, namely five (5), which means that the quality of service expected by the respondent is high. Based on these dimensions, it can be seen that the highest value is in the reliability dimension with a value of 4.89 , while the lowest value is in the tangibels dimension with a value of 4.7. This illustration shows that the responsiveness aspect is very important for respondents.

Table 4.

The level of importance of each dimension

\begin{tabular}{cccc}
\hline \hline Not. & Size & Score & Weight $(\%)$ \\
\hline 1. & Tangible & 4,7 & 19.40 \\
2. & Reliability & 4.89 & 20.40 \\
3. & Guarantee & 4.79 & 19.98 \\
4. & Empaty & 4.81 & 20.06 \\
5. & Responsiveness & 4.78 & 19.94 \\
& Average & 4.80 &
\end{tabular}

The results of data processing indicate that the average perceived service quality score is 3.54 . This score is in the somewhat unsatisfactory category, when compared with the average score of service quality score which is perceived to be lower than expected. This indicates a gap. The highest average score is given to responsiveness with a value of 3.62 while the lowest score is given to the dimension of empathy with a value of 3.44.

Table 5 .

Perceived service quality according to dimensions

\begin{tabular}{ccc}
\hline \hline Not. & Size & Score \\
\hline 1. & Tangible & 3.54 \\
2. & Reliability & 3.61 \\
3. & Guarantee & 3.49 \\
4. & Empaty & 3.44 \\
5. & Responsiveness & 3.62 \\
& total & 3.54
\end{tabular}

\section{DISCUSSION}

Based on the results of the research conducted, it was found that the hotel service satisfaction average score of perceived service quality was 3.54. This score is in the somewhat unsatisfactory category, when compared with the average score of service quality score which is perceived to be lower than expected. This indicates a gap. The highest average score is given to responsiveness with a value of 3.62 while the lowest score is given to the dimension of empathy with a value of 3.44. There is a result from the research that the form of services available at Swiss-BeliNN hotels is still found unsatisfactory service to visitors who come. From the research conducted also that the weaknesses of the research carried out were, The value of each predetermined criterion 
depends on the results of the interview form provided, where the accuracy of the data obtained is not in accordance with the existing facilities at the hotel, but even so, the form of the advantage of this research is the answer to a problem that has been sought by the leadership. in terms of which is the lack of the form of service at the hotel being managed. As a comparison of the references or references used in research, it is that previous research conducted had no results from the research obtained, but in this study the level of accuracy of the research was clearly visible in the research carried out. Where the accuracy of the data obtained is not in accordance with the existing facilities at the hotel, but even so the form of the advantages of this study is the answer to a problem that has been sought by the leadership in terms of which are the shortcomings of the form of service at the managed hotel. As a comparison of the references or references used in research, it is that previous research conducted had no results from the research obtained, but in this study the level of accuracy of the research was clearly visible in the research carried out. Where the accuracy of the data obtained is not in accordance with the existing facilities at the hotel, but even so the form of the advantages of this study is the answer to a problem that has been sought by the leadership in terms of which are the shortcomings of the form of service at the managed hotel. As a comparison of the references or references used in research, it is that previous research conducted had no results from the research obtained, but in this study the level of accuracy of the research was clearly visible in the research carried out.

\section{CONCLUSION}

Based on the description of the problems previously raised, the results show that the level of customer satisfaction that occurs at each hotel visitor can be seen from the level of accuracy of the research results, namely the results of hotel service satisfaction to the end that the average perceived service quality score is 3.54 . This score is in the somewhat unsatisfactory category, when compared with the average score of service quality score which is perceived to be lower than expected. This indicates a gap. The highest average score is given to responsiveness with a value of 3.62 while the lowest score is given to the dimension of empathy with a value of 3.44. With the application that is designed and from the results of the analysis carried out, it is obtained a percentage of the level of visitor satisfaction with the hotel visited

\section{REFERENCES}

Arianto, N. (2018). EFFECT OF SERVICE QUALITY ON VISITORS SATISFACTION AND LOYALTY IN USING HOTEL SERVICES RIZEN KEDATON BOGOR. Journal of Competitive Marketing. https://doi.org/10.32493/jpkpk.v1i2.856

Ekasari, R., Pradana, MS, Adriansyah, G., Prasnowo, MA, Rodli, AF, \& Hidayat, K. (2017). Analysis of Puskesmas Service Quality with Servqual Method. Darussalam Journal: Journal of Education, Communication and Islamic Legal Thought. https://doi.org/10.30739/darussalam.v9i1.118

Fakhriani, R., \& Rimiyati, H. (2016). ANALYSIS OF CONSUMER SATISFACTION PERCEPTION IN EFFORTS TO IMPROVE QUALITY OF Inpatient Services at PKU MUHAMMADIYAH GOMBONG Hospital. Journal of Medicoeticolegal and Hospital Management. https://doi.org/10.18196/jmmr.5101

FA Sianturi et al., "Decision Support System for the Determination of Credit Eligibility for Cooperative Members (Case Study at Kozero Cooperative)," Tek. Inform. Unika St. Thomas, vol. 02, pp. 88-100, 2017.

Fricles Ariwisanto Sianturi, "APPLICATION OF THE SIMPLE ADDITIVE WEIGHTING (SAW) METHOD IN SUPPORTING SYSTEM DECISION FOR EMPLOYEE SHIFT DECISION (CASE STUDY: RS.BHAYANGKARA TK.II MEDAN," J. Inf. Komput. Log., Vol. I, no. 2, pp. 43-47, 2019.

Hutauruk, YR (2016). Food Quality And Guest Satisfaction At Griya Hotel Medan. Http://E-Journal.SariMearl.Ac.Id/Index.Php/JMM/Article/Download/678/601/.

Kaswan. (2017). understanding of job satisfaction. Journal of Chemical Modeling and Information.

M. Fahmi and FA Sianturi, "ANALYSIS OF APRIORIC ALGORITHM ON CONSUMER ORDERING AT CAFÉ THE L. COFFE, "SAINTEK (Journal of Science and Technology, vol. 1, no. 1, pp. 52-57, 2019.

MS Fricles Ariwisanto Sianturi, "COMBINATION OF THE IMPORT DITIVEWEIGHTING (SAW) METHOD WITH NEAREST NEIGHBOR ALGORITHM FOR EMPLOYEE RECRUITMENT," Mantik Penusa, vol. 3, no. 2, pp. 1-9, 2019.

Prananda, Y., Lucitasari, DR, \& Abdul Khannan, MS (2019). IMPLEMENTATION OF SERVICE QUALITY (SERVQUAL) METHODS TO IMPROVE CUSTOMER SERVICE QUALITY. SELECTION. https://doi.org/10.31315/opsi.v12i1.2827

Sabariah. (2015). The Effect of Service Quality on Household Customer Satisfaction at PT. PLN (Persero) Rayon Samarinda Ulu. Journal of State Administration Science.

Susepti, A., Hamid, D., \& Kusumawati, A. (2017). EFFECT OF SERVICE QUALITY ON HOTEL GUEST SATISFACTION AND LOYALTY (Study of Guest Perception of Hotel Mahkota Plengkung, 
Banyuwangi Regency). Journal of S1 Business Administration Universitas Brawijaya.

Susilo, H., Haryono, AT, \& Mukery, M. (2018). Analysis of the Influence of Price, Service Quality, Promos, and Trust on Customer Satisfaction with Visit Decisions as Intervening Variables at Hotel Amanda Hills Bandungan. Journal of Management Unpad.

V. Mayora, B. Ginting, and FA Sianturi, "LABORATORY USING SIMPLE ADDITIVE WEIGHTING (SAW) METHOD IN GRANMED HOSPITAL," J. Inform. Pelita Nusant., Vol. 4, no. 2, pp. 1-7, 2019. 